\title{
2 \\ Libertarianism and the Problem of Flip-flopping
}

\author{
John Martin Fischer
}

\section{Introduction}

We should evaluate views on free will and moral responsibility in terms of a philosophical cost-benefit analysis. The benefits of a view must be carefully weighed against its costs. My main topic here is one alleged cost of libertarianism: it appears to imply that our status as free agents who are morally responsible for our behavior 'hangs on a thread.' Libertarianism depends on whether the (arguably) empirical thesis of causal determinism is true. The problem is not that our status as free agents would depend on an empirical thesis as such-it is that our status would depend on that sort of empirical thesis. Specifically, our free agency would depend on whether the laws of nature have associated with them 100 percent probabilities, instead of 95 percent or 99 percent probabilities. It seems curious that this sort of difference should change our status as free and morally responsible agents.

I am going to argue that it is a cost of libertarianism that it holds our status as agents hostage to theoretical physics, but that claim has met with disagreement. Some libertarians regard it as the cost of doing business, not a philosophical liability. By contrast, Peter van Inwagen has addressed the worry head on. He says that if he were to become convinced that causal determinism were true, he would not change his view that humans are free and morally responsible. Rather, he would give up at least one of the formerly-thought-to-be a priori truths that are elements in his argument for the incompatibility of causal determinism and the relevant sort of freedom. Thus, according to van Inwagen, our status as free and morally responsible agents would not be held hostage to the physicists or hang on a thread.

I think that van Inwagen's strategy for securing our freedom and responsibility is unattractive. Somewhat tendentiously, I have called the rejection of an a priori ingredient in the incompatibilist's argument, contingent upon learning that causal determinism is true, 'metaphysical flip-flopping.' And it does seem that van Inwagen's approach

\footnotetext{
${ }^{1}$ The term 'metaphysical flip-flopping' was introduced in Fischer and Ravizza 1998, 253-4.
} 
is implausible insofar as he is open to such metaphysical flip-flopping. That he is open to it-that he would flip-flop if he became convinced of the truth of causal determinism-is a problem for his actual philosophical position. Or so I will argue.

In this essay, I will try to pinpoint and elaborate the problem with metaphysical flip-flopping. I'll thus defend the contention that libertarian views face the worry that they render our status as free and responsible agents unduly at the mercy of certain discoveries of the physicists. I will also argue that libertarian theists-libertarians who also believe in God-are subject to a structurally parallel worry. That is, given the rejection of the strategy involving the possibility of metaphysical flip-flopping, libertarian theists would appear to have to give up their belief in God, if they were convinced that causal determinism were true. But, again, this is a significant price to pay for one's view about the conditions for free will: one's religious views would be held hostage to a certain sort of empirical discovery. Given the nature of religious beliefs and the nature of this sort of empirical discovery - that, say, the laws of nature have associated with them 100 percent probabilities rather than lower ones-it seems implausible that the religious beliefs should be held hostage to the possibility of the empirical discovery. The upshot of the discussion is to highlight one cost of libertarianism, which must be placed on the scales when evaluating positions on free will. Of course, no view comes without its costs, and the cost I will be highlighting is only one among a wider set of considerations. Nevertheless, I contend that this cost of accepting libertarianism is not insignificant.

\section{The Consequence Argument}

As I use the term here, libertarianism is the doctrine that human beings are free in the sense required for moral responsibility and that such freedom is incompatible with causal determinism. I further stipulate, at least for this part of the discussion, that the freedom in question involves freedom to do otherwise. To draw the problem with flip-flopping into view, I'll consider an influential and highly plausible argument for the incompatibility of causal determinism and freedom to do otherwise. This is one version-a 'modal' version-of a family of arguments called the 'Consequence Argument,' so named by Peter van Inwagen to mark the fact that under causal determinism, all of our choices and actions are the (deterministic) consequences of the past and the laws of nature. ${ }^{2}$

The version of the Consequence Argument I shall present is a 'modal' version because it employs a certain modal principle: the Principle of the Transfer of Powerlessness. ${ }^{3}$ In stating this principle, it will be helpful to have some definitions at hand. When a proposition $p$ obtains and a person $S$ does not have it in his power so to act that $p$ would not

\footnotetext{
2 Van Inwagen 1983.

${ }^{3}$ In the presentation of the modal version of the Consequence Argument, I draw heavily on Fischer and Ravizza 1998, 18-21.
} 
obtain, I'll say that $p$ is 'power necessary' relative to $S .{ }^{4}$ Power necessity is that kind of necessity which implies that a person does not have control over whether a proposition is true. When a proposition is power necessary relative to a person, the proposition in fact obtains and the person has 'no choice' about whether the proposition obtains. The abbreviation, ' $\mathrm{N}_{S, T}(p)$ ' will stand for: it is power necessary for $S$ at time $T$ that $p$-that is, $p$ obtains and $S$ is not free at $T$ to perform any action such that if $S$ were to perform it, $p$ would not obtain.

Consider now the Principle of the Transfer of Powerlessness:

1. If $\mathrm{N}_{S, T}(p)$ and

2. $\mathrm{N}_{S, T}$ (If $p$, then $\left.q\right)$, then

3. $\mathrm{N}_{S, T}(q)$.

Roughly, the principle says that if a person is powerless over one thing, and powerless over that thing's leading to another, then the person is powerless over the other. Slightly more carefully, the principle says that if $p$ obtains and a person $S$ cannot so act that $p$ would be false, and $S$ cannot so act that it would be false that if $p$ then $q$, then $q$ obtains and $S$ cannot so act that $q$ would be false.

A second ingredient in the modal version of the Consequence Argument captures the intuitive idea that the past is currently 'fixed' and out of our control. Here is one way of putting the idea: no person can act in such a way that some fact about the past would not have been a fact. Put differently, the thought is that if a person's performing a certain action would require some actual fact about the past not to have been a fact, then the person cannot perform the act. This might be called the Principle of the Fixity of the Past.

A further ingredient captures the similar idea that the laws of nature are fixed and out of our control. Intuitively, no human being can act in such a way that some natural law would not be a law. In other words, the Principle of the Fixity of the Laws says that if a person's performing a certain action would require that some actual natural law not be a law, then the person cannot perform the act.

Let's define causal determinism as the thesis that implies (whatever else it implies) that, for any given time, a complete statement of the facts about that time, together with a complete statement of the laws of nature, entails every truth as to what happens afterwards. Now the modal version of the Consequence Argument can be stated informally as follows. Suppose that causal determinism obtains and that some ordinary agent, Wilson, does something at a certain time: he mows his lawn on Wednesday afternoon. It follows from causal determinism that conditions obtaining in the past (say, on Monday), together with the laws of nature, entail that Wilson mows his lawn on Wednesday afternoon. And since Wilson has no control over the past, and Wilson has no control over the laws of nature, it follows (given the Principle of the Transfer of Powerlessness) that Wilson is not free between Monday

\footnotetext{
${ }^{4}$ The term 'power necessary' was introduced by Carl Ginet. See Ginet 1980, 171-86.
} 
and Wednesday afternoon (say, on Wednesday morning) to refrain from mowing on Wednesday afternoon.

A slightly more careful statement of the argument is in order. Given that causal determinism is true, there is some statement of the conditions of the world at $T 1, b$, which, together with the laws of nature, entails that $S$ does act $A$ at T3. Since nobody has control over the past,

1. $\mathrm{N}_{S, T 2}(b$ at $T 1)$.

And since nobody has control over the laws of nature,

2. $\quad \mathrm{N}_{S, T 2}$ (If $b$ at $T 1$, then $S \operatorname{does} A$ at T3).

Thus, by the Principle of the Transfer of Powerlessness, it follows that

3. $\mathrm{N}_{S, T 2}(S$ does $A$ at $T 3)$.

The argument employs plausible ingredients to reach the result that causal determinism is incompatible with freedom to do otherwise-the freedom that most libertarians presume is required for moral responsibility. There are other versions of the Consequence Argument, but for our purposes this modal version will do.

\section{Van Inwagen's Flip-flopping}

The Consequence Argument's conclusion-that causal determinism is incompatible with free will, in the sense presumed to be required for moral responsibility-is disturbing. After all, causal determinism is an empirical thesis that might turn out to be true. We do not know for certain that it is false, and so our status as free and morally responsible agents is called into question.

As already noted, van Inwagen has a strategy that seeks to secure our fundamental status as free and morally responsible. He says that in the unlikely event that he were convinced of the truth of causal determinism, he would not conclude that, despite appearances to the contrary, we are not in fact free and morally responsible. Rather, he would give up one of the previously-thought-to-be a priori true elements of the Consequence Argument. Van Inwagen says that he would reject what I have called the Principle of the Transfer of Powerlessness (van Inwagen's 'Principle Beta'). He writes:

I have defended [Beta, i.e. the Principle of the Transfer of Powerlessness] entirely on a priori grounds. But it would not surprise me too much to find that this proposition, which at present seems to me to be a truth of reason, had been refuted by the progress of science. Such refutations have happened many times. And it does not follow from the fact that they have happened that there is anything wrong with accepting on a priori grounds a principle that later turns out to be empirically refutable. One must simply realize that $a$ priori convictions are as corrigible as any others. ${ }^{5}$ 
This strikes me as problematic. Van Inwagen's willingness to reject the modal transfer principle merely on the supposition that he would become convinced of the truth of causal determinism is unappealing - it makes for bad epistemology. I hope to explain the source of my concern.

Notice first that there appears to be a difference between the dialectical situation here and the sorts of situations van Inwagen envisions when he writes of principles that had appeared to be truths of reason but were then 'refuted by the progress of science.' Let's say there is a principle $P$ that we take to be an a priori truth. Science gradually progresses to the stage where $P$, joined with newly developed scientific principles, entails some further proposition that is clearly and indisputably empirically refutable. Then we would rightly abandon what we once took to be an a priori true principle.

Importantly, our giving up principle $P$ in the envisaged context is different than van Inwagen's giving up the modal principle in the Consequence Argument upon discovering that causal determinism is true. The Principle of the Transfer of Powerlessness is initially regarded as a priori true, but then science marches onward and causal determinism is established as true. So now scientific principles, causal determinism included, as well as the modal principle, entail that we are not free and morally responsible. Although van Inwagen wishes to resist this entailment because he's so confident that we are free and morally responsible, it is not clearly and indisputably empirically refutable that we lack freedom and moral responsibility. That's a crucial difference between the two contexts. Whether we are free and morally responsible is controversial and can't be settled by empirical means alone. (One more thing: the entailed putatively empirical proposition is precisely the proposition at issue in the dialectical context; it then seems especially problematic to employ an antecedent view about this proposition as part of a project of 'reverse engineering' the argument.) To be sure, we sometimes sensibly rethink our commitment to principles earlier deemed $a$ priori truths, as we see in the example involving principle $P$. But that fact does not by itself make the disposition to metaphysical flip-flopping appropriate for van Inwagen.

In An Essay on Free Will, van Inwagen discusses the problems associated with indeterministic conceptions of freedom and moral responsibility. He admits that it is 'puzzling' how an agent can genuinely be in control of his behavior, given indeterminism (in the relevant places along the sequence). But he also admits that it is nevertheless 'inconceivable' that causal determinism is compatible with freedom and moral responsibility. Van Inwagen is quite confident that we are indeed free and morally responsible even though he can't fully explain how we are. And so he confesses: 'I must choose between the puzzling and the inconceivable. I choose the puzzling.'

But is this right? Is it really inconceivable for van Inwagen that causal determinism is compatible with freedom and moral responsibility? After all, as I've already noted, he has written that, if he were to be convinced of the truth of causal determinism, he would give up the Principle of the Transfer of Powerlessness and embrace compatibilism. My

6 Van Inwagen 1983, 150. 
question is simple: how then could it be inconceivable that compatibilism is true? Perhaps van Inwagen's point is that at the present moment-in the absence of a compelling reason to accept causal determinism-it is inconceivable to him that compatibilism is also true, but that if he were convinced of the truth of causal determinism, it would (under those rather different circumstances) be conceivable to him that compatibilism is true. But this seems strange and a little awkward. If it would be conceivable under the envisaged circumstances that compatibilism is true, why isn't it now so conceivable, even in the absence of a belief in causal determinism? If one believes that under the counterfactual circumstances in question, there would be no barrier to conceiving of the truth of compatibilism, why is there now a barrier to conceiving of the truth of compatibilism? The change in the circumstances appears to be irrelevant to the conceivability of compatibilism. So why not 'bring it home'? That is, why not 'bring home' the claim about conceivability to the present circumstance?

Recall that van Inwagen sums up his theoretical choice as follows: 'I must choose between the puzzling [libertarianism] and the inconceivable [compatibilism]. I choose the puzzling.' But that isn't quite right. Van Inwagen can and should 'bring home' the conceivability of compatibilism, given what he says about his disposition to flip-flop, upon learning that causal determinism is true. But there is more to say here. I want to push even further and challenge van Inwagen's libertarianism itself. It's not clear why he shouldn't also 'bring home' belief in compatibilism to his current situation, given his flip-flopping disposition. Let us turn to that now.

\section{The Flip-flopping Problem}

Here is a quick initial statement of my argument. The disposition to flip-flop commits van Inwagen to this: if he were to learn that causal determinism ('determinism' for short) is true, he would reject the Principle of the Transfer of Powerlessness ('Principle' for short). Would he reject the Principle for no reason, aside from his desire to avoid the conclusion it would lead to, or would he have some reason to reject the Principle? Rejecting the Principle merely to avoid an unwanted conclusion seems problematic. And it likewise seems problematic to evaluate evidence differently simply to dodge an unwanted conclusion. So, I will assume that van Inwagen thinks that there would be some reason to reject the Principle, were he convinced that determinism is true. But then why would that reason only exist in the counterfactual scenario? Switching from the actual situation (where van Inwagen doesn't believe that determinism obtains) to the counterfactual situation (where van Inwagen does believe that determinism obtains) doesn't appear to have any impact on the existence of the reason at issue. So, why not bring the reason home? And thus why not bring compatibilism home, too?

\footnotetext{
${ }^{7}$ I am indebted to Michael Nelson for the suggestion that the 'bringing it home' metaphor applies to this sort of dialectical context; see Nelson 2011.

${ }^{8}$ Van Inwagen 1983, 150.
} 
That was impressionistic, but allow me to develop this argument in more detail. What is so perplexing to me about van Inwagen's position is: the truth of determinism doesn't clearly have anything to do with the Principle. Learning that determinism is true does not seem to call for a different view of the Principle. But, again, van Inwagen's view is that if he were to learn that determinism obtains, he would reject the Principle. How could this be a reasonable policy unless determinism is somehow evidentially related to the Principle?

Let me try out an initial thought on what the evidential relation might be. If learning that determinism is true would rationally change van Inwagen's assessment of the Principle, then that's because his evidence for the Principle depends on premises or assumptions that entail the falsity (or low probability) of determinism itself. In slightly different words: if by learning that determinism obtains, he would come to realize that the Principle needs a different assessment, then that's just because the Principle had led him all along to assume that determinism is false (or improbable). Once he learns that determinism is true, so much the worse for the Principle.

That seems to be one way that learning that determinism obtains could be evidentially related to the Principle. But this account of the evidential connection is problematic. What is it about the Principle (or van Inwagen's evidence for it) that presupposes that determinism is false? I haven't the foggiest idea. The two seem evidentially unrelated. So, the present account appears to propose an entirely ad hoc evidential connection.

Van Inwagen may say that learning that determinism is true is relevant to the Principle in the following way. For starters, notice the obvious: learning that determinism obtains, together with van Inwagen's evidence for incompatibilism (the Principle included), implies that humans lack free will and moral responsibility. If determinism is correct, and if van Inwagen's argument for incompatibilism is correct, there is no free will and moral responsibility. So, given what van Inwagen has learned about determinism from the physicists, there must be some defect in some part of the argument for incompatibilism-since he thinks, of course, that we must have free will and moral responsibility. The defect in his argument is one that has so far gone unappreciated by him, but it is a defect nonetheless, and learning that determinism is true has revealed it to him. The idea here is that learning that determinism obtains is evidentially relevant to van Inwagen's assessment of the Principle because learning that determinism is true indicates that the Principle sneaks a defect into the argument. Van Inwagen can now see that the Principle must be mistaken, even if he doesn't know what exactly the problem is.

It isn't obvious to me why learning that determinism obtains must rationally change van Inwagen's view of the Principle. We can grant that the Principle may have a hidden defect. But why must the defect rest right there? After all, the up-until-now unrecognized trouble may rest instead with commitment to free will and moral responsibility, not with the Principle. That is at least enough to show it's doubtful that there must be a defect with the Principle: learning that determinism is true, together with the argument for incompatibilism, does not entail that the Principle has a hidden defect, 
because there may instead be a hidden defect with commitment to free will and moral responsibility.

I suspect that it's in the spirit of van Inwagen's position to reason along the following lines. If he learns that determinism is true, he realizes that there must be a hitherto hidden defect with his position. Where is the defect? When surveying his evidence for his position, it seems clear to him that his evidence for the Principle is weaker than his evidence for any other ingredient in his position. So, given the varying degrees of strength of his evidence for the other ingredients, it seems clear to him that the hidden defect is more likely to be found in the Principle than in his commitment to our freedom and responsibility or anything else. Thus, when he learns that determinism is true, he can rationally revise his assessment of the Principle, given that the defect is most likely found there.

All of this offers an account of an alleged evidential connection between learning that determinism is true and the Principle. Learning that determinism is true is evidentially related to the Principle because learning as much reveals a hidden defect with the argument for incompatibilism and one that probably resides with the Principle. Even so, none of this makes van Inwagen's metaphysical flip-flopping look attractive, I think. Recall, once more, that van Inwagen says that if he were to learn that determinism is true, he would reject the Principle. This account of the evidential connection assumes that learning that determinism is true only reveals an up-until-now hidden defect with the Principle. What van Inwagen learns doesn't create the defect-it merely makes it known. But note well: the account thus implies that the Principle is problematic even before van Inwagen learns that determinism is true. So, by adopting this account of the evidential connection between learning that determinism is true and the Principle, van Inwagen must accept that the Principle is dubious. Therefore, in his actual situation, there is already reason to give up the Principle. And it would seem odd to suppose that, although there is already reason to give up the Principle, the reason only becomes decisive when van Inwagen discovers that causal determinism is true! That is, there is no evidential connection between discovering that causal determinism obtains and the Principle which is such that discovering that causal determinism obtains would put the evidence against the Principle 'over the top', as it were.

Contrast this situation with one provided in correspondence with Dan Speak, who writes:

Suppose I rebuild a classic car. In doing so, I had special trouble getting the transmission into form (it's an especially tricky part of the machine). So, before I turn the key to take it for an initial spin, I think to myself, 'If I can't get this thing to drive properly, the problem is likely with the transmission.' Does admitting this commit me to thinking that there is an actual problem with the transmission? Does it require me to give up my belief that the car will in fact run? It doesn't seem so.

I agree. But this is because there is some evidential connection (in the context) between the car's not running and the transmission's having a problem; the fact that it doesn't 
run, when you turn the ignition key, is further evidence that there is a problem with the transmission. In contrast, the fact that causal determinism obtains would not be further evidence that the Principle is false - or at least it is mysterious why this should be so. In the car case, you already suspect the transmission (for good reason). In the case of the argument for incompatibilism, van Inwagen does not already suspect the Principle; in fact, it is quite the contrary.

Let us take stock of my discussion of van Inwagen's argumentative approach thus far. Suppose that van Inwagen learns that determinism is true. One possibility, which I have left aside, is that there would be no reason to reject the Principle. Another possibility is that he has some reason to reject the Principle. I have explored what might allow him reasonably to reject it. The trouble, I think, is that if there is a reason to reject the Principle in the counterfactual scenario where physicists report that determinism is true, that reason is already present in the actual scenario. Thus, flip-flopping leads from libertarianism to compatibilism because it requires that there would be, and is, reason to reject the Principle.

Could there be another interpretation of van Inwagen's argumentative strategy that I have overlooked? Here is one possibility. ${ }^{9}$ Plausibly, van Inwagen actually finds it highly improbable that determinism is true. Under the actual circumstances, and given his belief-to which he attaches a high probability - that we are free and morally responsible, he deems it more likely that all of the ingredients in the Consequence Argument are true than that compatibilism is. But if he were-per improbabile-to be convinced that determinism is true, then it would be a matter of giving up the proposition to which he would, under those circumstances, attach the lowest probability. And if he were to believe that causal determinism is true, he would attach a lower probability to at least one of the ingredients in the Consequence Argument (namely, the Principle) than that we are not free and morally responsible. On this strategy, the idea is that van Inwagen is forced to reject at least one principle to which he had previously been attracted, and he rejects the least probable.

This strategy raises some similar issues to the ones I have already explored. What are the reasons for accepting certain principles and rejecting others? Going without reasons here seems problematic. But, given that van Inwagen has learned that determinism is true, why is it plausible that the belief in free will and moral responsibility would be assigned a higher probability than the Principle (or other ingredients in the Consequence Argument, such as the Principle of the Fixity of the Past or the Principle of the Fixity of the Laws)? This would seem to suggest excessive confidence in our freedom and responsibility and perhaps an unattractive complacency.

To elaborate. Even for van Inwagen, our status as free and morally responsible is not immune to empirical discoveries. He doesn't regard his belief in free will as empirically

\footnotetext{
${ }^{9}$ I am grateful to Derk Pereboom and Christopher Franklin for suggesting this possible interpretation of van Inwagen's approach.
} 
indefeasible - in the sense that it is supported by reasons that cannot possibly be removed or defeated by empirical reasons. For instance, while arguing against the 'Paradigm Case Argument,' van Inwagen writes that the following scenario is at least possible:

(M) When any human being is born, the Martians implant in his brain a tiny device-one that is undetectable by any observational technique we have at our disposal, though it is not in principle undetectable-which contains a 'program' for that person's entire life: whenever that person must make a decision, the device causes him to decide one way or the other according to the requirements of a table of instructions that were incorporated into the structure of the device before that person was conceived. ${ }^{10}$

He goes on to say:

If we should discover that some particular person-Himmler, say-acted as he did because a Martian device, implanted in his brain at the moment of his birth, had caused all his decisions, then we should hardly want to say that Himmler had free will, that he could have helped what he did, that he had any choice about the way he acted, or that he ever could have done otherwise. And I don't see why matters should be different if we discovered that everyone was 'directed' by a Martian device: then we should have to make these judgments about everyone. ${ }^{11}$

Of course, it is possible that van Inwagen would give up his association of moral responsibility with freedom to do otherwise, were he to become convinced of (M). But he doesn't endorse this move, and I will assume that, if he were to be convinced that $(\mathrm{M})$ were true, he would give up his view that we are free and morally responsible. And a similar point seems to apply to the discovery that determinism is true. Thus, van Inwagen's belief that we are free and morally responsible agents cannot be an empirically indefeasible belief-it can be challenged or defeated by empirical facts.

Martians and brain implants to the side, it would seem that our status as free agents can be called into question by other empirical hypotheses. Consider for instance the theses emerging from the 'situationist' and 'automaticity' literatures in psychology. According to certain interpretations of the experimental results, human behavior is largely driven by our emotions and 'cues' from our environment, not 'reasons.' If these contentions are true-and of course they are highly controversial—-then it would at least be plausible that our status as free and morally responsible agents would be called into question. More generally, and for many reasons, moral-responsibility skepticism is a 'contender' in the debates about free will and moral responsibility. To rule out such skepticism from the start is dialectically infelicitous (within the relevant dialectical context).

But van Inwagen might still insist that, in the event of his coming to be convinced that determinism were true, he would hold on to the belief in free will and moral 
responsibility and abandon his belief in the Principle. It is mysterious what would allow him to reject the Principle. As discussed earlier, it is unclear how he could sensibly give it up for no reason, and if there would be a reason to give it up, then it seems that there already is such a reason. But set this point aside. I claim that it is just unclear how van Inwagen could explain his preference for freedom and responsibility over the Principle. Antecedently anyway, it wouldn't seem obvious that our status as free and morally responsible agents stands on firmer footing than the Principle.

Here is a further point. I would contend that the Consequence Argument does not depend essentially on the Principle. That is, the Consequence Argument can be presented without explicit or implicit reliance on the Principle (or any related transfer of powerlessness principle). ${ }^{12}$ If I am correct on this point, then the only way van Inwagen could maintain that we are indeed free and morally responsible, were he convinced that determinism were true, would be to reject the Principle of the Fixity of the Past or the Principle of the Fixity of the Laws. But again it is completely unclear that these Principles are (or would be) less plausible than our status as free and morally responsible agents, or on what basis van Inwagen could reject them in order to maintain his belief in our freedom and moral responsibility.

The considerations I've offered reveal that, on the latest interpretation, van Inwagen's thinking is incomplete in important respects. Why would it be independently plausible, under the assumption of determinism - and apart from wishful thinking - that one should be less confident in the Principle than our status as free and morally responsible agents? And if, as I believe, the Consequence Argument does not depend on the Principle, why would it be independently plausible that our status as free and morally responsible agents should trump the Principles of the Fixity of the Past and the Laws?

Consider some of what van Inwagen says about the laws of nature:

It is quite conceivable that human power will grow to the extent that we shall one day be able to alter the stars in their courses. But we shall never be able to do anything about the laws of nature... [T] he laws of nature impose limits on our abilities: they are partly determinative of what it is possible for us to do. And indeed this conclusion is hardly more than a tautology. ${ }^{13}$

In light of his strong defense of the Principle of the Fixity of the Laws, how could he reasonably reject that principle in favor of our freedom and responsibility-highly contested notions indeed-if he were to be convinced that determinism obtains? Similar considerations also apply to the Principle of the Fixity of the Past.

12 Fischer and Ravizza 1996. It should be noted that Van Inwagen disagrees, claiming that all versions of the Consequence Argument depend on the Transfer Principle (his Principle Beta): see, for instance, van Inwagen 1983, 57 where he claims that the three versions of the argument he presents 'stand or fall together.'

13 Van Inwagen 1983, 61 and 62. 
To sum up. In light of my argument, it seems that van Inwagen cannot easily maintain his libertarianism. On one hand, if he keeps libertarianism, he's subject to the criticism that he is willing to hold to, or reject, putatively fundamental principles simply to get what he wants in the argument. This is dialectically uncomfortable. On the other hand, if van Inwagen can't flip-flop, then our fundamental status as free and morally responsible agents hangs on a thread. Freedom will be held hostage to the theoretical physicists. This is a significant cost of libertarianism.

\section{Libertarianism and Theism}

Just as it is uncomfortable to have one's most basic views about one's freedom and moral responsibility hang on a thread, it is likewise uncomfortable to have one's belief in God held hostage to the possible discovery that determinism is true. If one does believe in God, then presumably a belief in God is a central feature of one's intellectual and affective orientation. So, it is a strike against a position that it so conceptualizes freedom that someone would have to give up her belief in God, if determinism were true. Given that flip-flopping (or the disposition to do so) is not an option, then the libertarian must indeed give up her belief in God, under the circumstance in which she becomes convinced that determinism is true.

Let us focus on a libertarian who is also a theist. And allow me to stipulate-what is certainly not implausible-that the theist holds that belief in human freedom is necessary in order to justify or defend belief in God. Perhaps the theist holds that only those individuals who freely accept God's forgiveness could legitimately be saved, or that only those individuals who freely reject it can be damned. Or perhaps the theist holds that free will is a key component of a defense against the problem of evil. In any case, I shall simply assume that the theist I'm talking about must hold that human beings are free. I'll make use of the shorthand: theism requires freedom.

Given that theism requires freedom, and that flip-flopping is not an acceptable option, it would seem that a libertarian theist would have to give up her belief in God, if she were to learn that determinism holds. But then one of the libertarian theist's most central and fundamental beliefs will be held hostage to whether the natural laws have associated with them 100 percent probabilities or something less. And this seems uncomfortable.

Now it might be objected that a true belief in a certain sort of God would entail the falsity of determinism. If one believed in a God who has the power to intervene in the world and prevent events that otherwise would have occurred, then it would follow that determinism is necessarily false insofar as the required entailments from truths about the past to truths about the present won't be secured. After all, given that such-and-such occurred in the past, it is still open to God to intervene 
and thus disrupt the expected connection between such-and-such in the past and so-and-so in the future. So, perhaps a libertarian theist can avoid the problem that her theism hangs on a thread by claiming that determinism is necessarily false.

Leaving aside the implausibility of claiming that determinism is necessarily false (and that we can know this from our armchair, as it were), I don't think that this move will help the libertarian theist. Note that what is envisaged is that God has the power to intervene to prevent an agent from behaving as he otherwise would have; but clearly if God were to exercise this power, God would thereby obliterate the agent's libertarian freedom. And this fact helps to generate an argument for the lack of (libertarian) freedom in such a scenario.

We can suppose, then, that causal conditions are such that the entailments would go through but for the existence of God (construed as above). Let's also suppose that a God who has the power to intervene in the world exists. Now we assume that Wilson mows his lawn on Wednesday afternoon. Given the assumptions above, we also know that if Wilson had done otherwise (i.e. if Wilson had held off mowing his lawn on Wednesday), then either the past would have been different, some actual law of nature would not have obtained, or God would have intervened. But if Wilson's doing otherwise would require the past to have been different, then it is at least plausible that he was not able to do otherwise (from the Principle of the Fixity of the Past). And if Wilson's doing otherwise would require the laws to have been different, then it was at least plausible that he was not able to do otherwise (from the Principle of the Fixity of the Laws). And if Wilson's doing otherwise would have been as a result of God's intervention, then Wilson surely lacked the power to do otherwise in the sense in question. That is to say, in this scenario he would not have libertarian freedom, in the sense required for moral responsibility.

Thus, the libertarian theist is not helped by invoking the thought that, assuming theism, determinism would be necessarily false. And given the unavailability of a disposition toward metaphysical flip-flopping (of the sort discussed earlier), a libertarian theist would always be in an uncomfortable spot. She would have to give up her belief in God, if the scientists were to show that determinism were true. I contend that this is a significant, if not decisive, cost of libertarianism, when the view is joined with theism.

\section{Conclusion}

I have argued that metaphysical flip-flopping is untenable. Thus, some of the most fundamental beliefs held by libertarians-about freedom, moral responsibility, and perhaps God-are in jeopardy. These important beliefs 'hang on a thread,' in the sense that we would have to abandon them, given an acceptance of libertarianism, if scientists were to convince us that causal determinism is true. One advantage of compatibilism, 
in all of its forms (classical and semicompatibilism), is that it does not put these fundamental beliefs at risk as libertarianism does. ${ }^{14,15}$

\section{References}

Ginet, Carl. 1980. 'The Conditional Analysis of Freedom.' In Time and Cause: Essays Presented to Richard Taylor, edited by Peter van Inwagen. Dordrect: D. Reidel.

Fischer, John Martin, and Mark Ravizza. 1996. 'Free Will and the Modal Principle.' Philosophical Studies 83: 213-30.

Fischer, John Martin, and Mark Ravizza. 1998. Responsibility and Control: A Theory of Moral Responsibility. New York: Cambridge University Press.

Nelson, Michael. 2011. 'Default Compatibilism and Narrativity: Comments on John Martin

Fischer's Ways and Stories.' Social Theory and Practice 37: 35-4.

Van Inwagen, Peter. 1983. An Essay on Free Will. Oxford: Clarendon Press.

${ }^{14}$ I have contended that the benefits of a philosophical view should be carefully weighed against its costs. Are there any extra benefits of libertarianism that enjoys, or extra costs of compatibilism, in light of our discussion? For theists, the problem of evil may seem to be easier to manage on libertarianism than on compatibilism. As a matter of fact, theists have occasionally argued that the problem of evil is insoluble given the assumption of determinism, and, if that's so, the problem of evil offers reason to favor libertarianism over compatibilism.

I do not agree, but a full discussion is beyond the scope of this paper. So let me be brief. As regards human freedom, the compatibilist (and even the semicompatibilist) can hold that human beings have it in a deterministic world; indeed, the theorist can presumably attribute it to agents in just the same places as the libertarian would (in an indeterministic world). But wouldn't it follow from determinism that God is the author of all evil, and thus morally blameworthy for all evil? Again, I think not. True, on this picture, God would arguably be the author (causal source) of all evil, and presumably God would also be morally accountable for it. But moral accountability need not imply blameworthiness (even for evil upshots). Whether God is morally responsible or accountable for an upshot is one thing, and whether God is blameworthy for it is quite another. And whether God is blameworthy is presumably a complicated question having to do with whether, despite the evil, this is the best of all possible worlds. Here I see no reason why the compatibilist can't appeal to the same considerations that a libertarian could about how evil fits into the overall scheme of things. How a given defense or theodicy will fare lies beyond the scope of this paper. The suggestion here is simply that, arguably, a compatibilist is no worse off than an incompatibilist here.

${ }^{15}$ For comments on an earlier version, I am grateful to Andrew Bailey, Christopher Franklin, Derk Pereboom, Joshua Rasmussen, Kevin Timpe, Jada Strabbling, and Dan Speak. A previous version was presented at a conference ('Free Will and the Scientific Worldview: Optimistic and Pessimistic Perspectives') sponsored by the Center for Science, Ethics, and Public Policy at the University of Delaware, Newark: thank you to the audience for helpful discussion. I am especially indebted to detailed and extremely insightful comments by Nathan Ballantyne. 